\section{ESTRATÉGIAS DE CONSTRUÇÃO DE VÍNCULOS NAS REDES SOCIAIS DIGITAIS E AS NOVAS FORMAS DE HIDRIBRIZAÇÃO DE CONTEÚDOS AUDIOVISUAIS}

O número 2, volume 8, 2016, da Signos do Consumo apresenta conjunto de artigos que tematizam as relações de consumo com discussões sobre linguagens e suportes variados (como TV, Internet e redes digitais), além de problematizar as estratégias para construção de vínculos de sentido entre pessoas e marcas nesses espaços. Com ênfase no estudo do Facebook, maior rede social no Brasil, mas também discutindo hábitos, características, táticas e tendências de linguagem (como memes, posts, ativismos) e articulação com outros suportes, como uso de smartphones, conteúdos interativos para TV e portais etc., apresenta os caminhos que gestores e produtores de conteúdos de marcas estão buscando para ampliar os pontos de contato com consumidores.

Uma vez mais, a edição integra conteúdos de diversos pesquisadores da pós-graduação em comunicação no país, com contribuições dos estados do Rio de Janeiro, Brasília, Rio Grande do Sul, Minas Gerais e São Paulo.

O primeiro texto deste número, de Deborah Rodriguez, da Universidade Federal Fluminense (UFF), traz reflexão sobre as práticas de ativismo virtual da comunidade Mujeres en Círculo na rede Facebook, utilizando-se de abordagem etnográfica como método privilegiado. Apresenta e avalia a importância dessas ações na rede para construção do empoderamento de mulheres, que conseguem nesse espaço subverter as lógicas das narrativas patriarcais e machistas tradicionais, por sentirem-se mais seguras e encorajadas a assumir posições e ideologias. Trata-se de importante contribuição para os estudos da mulher na articulação com os processos de midiatização de conteúdos digitais.

Já Antonio Hélio Junqueira, da Universidade Anhembi-Morumbi, apresenta o texto "Os memes e suas aproximações pelo marketing digital: a experiência da rede brasileira de fast-food Giraffas”. A pesquisa teve como objetivo central analisar diversas experiências e abordagens do marketing digital, enfatizando o uso de memes como técnica de comunicação mercadológica empresarial. Adicionalmente, buscou contribuir para o conhecimento científico de usos, abrangências, potencialidades e limites dos memes levando em conta sua potencial efetividade e eficácia em ações promocionais de marcas, produtos e serviços nas novas mídias sociais digitais, uma vez que instauram linguagem afetiva e de bom humor, caminho comunicacional que tem se provado eficiente na contemporaneidade, pela abertura e positividade que instaura.

"Vem aí na Globo uma nova programação" é artigo resultante da pesquisa de pós-graduação levada a cabo por Gabriel Souza e Maria Lília Dias de Castro, da Universidade Federal de Santa Maria (UFSM), no Rio Grande do Sul. O texto objetiva examinar, por meio da semiótica discursiva europeia, os desdobramentos propostos pelos seguidores do programa Vem Aí na TV Globo, de 2013. O programa visava apresentar toda a programação do ano da emissora, assim se configurando como o principal veículo promocional.

Como citar este artigo:

PEREZ,C.; TRINDADE, E. Estratégias de construção de vínculos nas redes sociais digitais e as novas formas de

hidribrização de conteúdos audiovisuais. Signos do Consumo, São Paulo, v. 8, n. 2, p. 1-3, jul./dez. 2016. 
O autor busca refletir sobre as estratégias comunicativas e discursivas adotadas pela emissora por meio da utilização de novos e antigos programas para construir um novo produto audiovisual (absolutamente autorreferencial) e divulgar sua programação, com importante poder de persuasão.

Dani Gurgel, da Escola de Comunicações e Artes (ECA-USP), apresenta discussão sobre as mudanças estruturais no consumo de música, com "O novo público da indústria musical: aquele que compra ou aquele que escuta?”. Enfatiza a discussão acerca do crescimento das vendas digitais, bem como a mudança do uso de pirataria para o streaming, o que acabou por alterar completamente o paradigma sobre quem de fato é o target da indústria musical. A reflexão nos leva ao entendimento de que passamos de um público que compra o produto fonográfico para aquele que escuta e gera renda de outras formas.

Os pesquisadores Beatriz Braga Bezerra e Rafael Ofemann, ambos da Escola Superior de Propaganda e Marketing de São Paulo (ESPM), apresentam o texto "Humor, ironia e intertextualidade: produção e consumo na série Narcos no Facebook". Contribuem para importante reflexão acerca da consolidação das webséries como prática cultural contemporânea, alicerçadas em novos modelos de negócio e também novas possibilidades de consumo no âmbito dos produtos audiovisuais. O foco da discussão tem como base a página de Narcos no Facebook, que é analisada detalhadamente, permitindo-se inferir as estratégias de informação e formação de vínculos com os públicos a partir da articulação de conteúdos em múltiplas plataformas e suas hibridizações.

Edmundo Brandão Dantas e Priscila Valim Carneiro Vidal, da Universidade de Brasília, apresentam "Dependência mobile: a relação da nova geração com os gadgets móveis digitais”, que tematiza a relação das gerações $\mathrm{Z}$ e Y com os dispositivos móveis digitais, sistematizando as descobertas verificadas a partir de estudo exploratório e descritivo realizado sobre a interação dessas gerações com o smartphone. O objetivo foi verificar se a geração $\mathrm{Z}$ apresenta maior grau de dependência a esses dispositivos que a geração anterior, a Y. Além de pesquisa bibliográfica e documental, foi realizada pesquisa de campo, no Distrito Federal, por meio de abordagem quanti-qualitativa, utilizando-se de questionários e relatos testemunhais de jovens impedidos de utilizar seus celulares por certo período de tempo. A pesquisa nos levou a crer que há maior dependência da geração $\mathrm{Z}$ que a geração anterior, embora a diferença não seja substancial. Destacado resultado inspira questões amplas, desde o aprofundamento da "dependência” desses jovens até o uso dessa condição pelas marcas, suscitando questões éticas muito necessárias no âmbito da pesquisa em comunicação.

Eugênio Bucci, professor da Escola de Comunicações e Artes (ECAUSP), apresenta "A imprensa, o consumo (de informação, inclusive) e o fetiche da tecnologia”. O artigo é fruto de reflexão teórica visando tematizar o impacto das novas tecnologias sobre a percepção de profissionais, usuários e pesquisadores do jornalismo, da publicidade e da comunicação social de modo geral. O autor parte da localização de pontos de conexão entre o universo da imprensa e a sociedade de consumo, lócus este mediado por técnicas e estratégias comunicacionais específicas da publicidade e das relações públicas. Resgata, na história recente, depoimentos de pensadores sobre o advento das chamadas mudanças disruptivas, com o objetivo de mostrar primeiramente que a sensação de que as coisas nunca mudaram tão depressa data pelo 
menos de alguns séculos, e, segundo, que é preciso prudência para não idolatrar as inovações da técnica como se fossem o útero do futuro. É uma reflexão crítica e madura sobre o estado da arte da comunicação contemporânea, partindo do lugar do jornalismo, mas na articulação com o consumo.

Esta edição da Signos se encerra com o artigo de Pablo Moreno Fernandes Viana, professor da Pontifícia Universidade Católica de Minas Gerais, com o texto "Cerveja e notícias híbridas: publieditoriais no G1”. As reflexões do autor têm início com a constatação do profundo processo de complexificação pelo qual vem passando a publicidade nos últimos anos. Cada vez mais híbridas, multiplataformas e com foco na relevância dos conteúdos, os publieditoriais, textos publicitários apresentados na forma de notícia, vêm sendo interessante solução. A partir da análise de publieditorial no G1, do anunciante Empório da Cerveja, foi possível identificar que a forma de comunicação que equilibra conteúdo jornalístico e publicidade, com influência do jornalismo cultural, favorece a construção de imaginários consistentes e atinentes aos contextos sígnicos das marcas, além de estimular a experiência de consumo, sem necessariamente fazer menções explícitas ao anunciante.

Além dos oito artigos, há ainda nesta edição duas resenhas de obras importantes para as pesquisas em comunicação e consumo. Gustavo da Silva Tristão apresenta a resenha "A centralidade do consumo na sociedade contemporânea”, sobre livro de Lívia Barbosa e C. Campbell, Cultura, consumo e identidade, editado no Brasil em 2006. E Mauricio Gomes de Faria nos oferece "O consumo na América Latina e a formação de identidades transterritoriais", sobre Consumidores e cidadãos, livro de Néstor Garcia Canclini que trata dos conflitos multiculturais da globalização e os transbordamentos de sentido na construção e sustentação das identidades.

Encerramos o ano de 2016 satisfeitos com os avanços editoriais obtidos, materializados tanto na reformulação editorial da revista, nos processos de avaliação, seleção e divulgação dos artigos, como também na expansão do número de textos submetidos, o que permite melhorias nos critérios de avaliação e melhor adequação à linha temática. Novos desafios se apresentam para 2017, sendo que um deles terá nossa dedicação especial, que é a obtenção de outros indexadores editoriais para a melhoria contínua da Signos do Consumo e, consequentemente, melhor qualidade dos textos divulgados.

Boa leitura, e um 2017 só de coisas boas a todos os nossos leitores! 